\title{
ON THE THEORY OF FUNDAMENTAL NORMING BOUNDED BIORTHOGONAL SYSTEMS IN BANACH SPACES
}

\author{
PAOLO TERENZI
}

\begin{abstract}
Let $X$ and $Y$ be quasi complementary subspaces of a separable Banach space $B$ and let $\left(z_{n}\right)$ be a sequence complete in $X$. Then

(a) there exists a uniformly minimal norming $M$-basis $\left(x_{n}\right)$ of $X$ with $x_{m} \in$ $\operatorname{span}\left(z_{n}\right)_{n \geq q_{m}}$ for every $m, q_{m} \rightarrow \infty$;

(b) if $\left(x_{n}\right)$ is a uniformly minimal norming $M$-basis of $X$, there exists a uniformly minimal norming $M$-basis of $B$ which is an extension of $\left(x_{n}\right)$;

(c) there exists a uniformly minimal norming $M$-basis $\left(x_{n}\right) \cup\left(y_{n}\right)$ of $B$ with $\left(x_{n}\right) \subset X$ and $\left(y_{n}\right) \subset Y$.
\end{abstract}

Introduction. The problem of the best complete sequence in a separable Banach space appears already in Banach's book [1]. The story of this problem goes through the existence of the $M$-basis (Markushevich [7], 1943), the existence of the norming $M$-basis (Mackey [6], 1946) and other intermediate results (DavisJohnson [2], 1973); it culminates with a negative answer to the basis problem (Enflo [3], 1973) and with the existence of the uniformly minimal norming $M$-basis (Ovsepian and Pełczynski [9], 1975; refined by Pełczynski [10], 1976).

The aim of this note is to study particular constructions of uniformly minimal norming $M$-bases.

In this direction three types of questions appear:

(i) The regularization of a sequence $\left(x_{n}\right)$ of $B$ with $\left[x_{n}\right]$ of infinite dimension; indeed, by [9] there exists a uniformly minimal norming $M$-basis $\left(z_{n}\right)$ of $\left[x_{n}\right]$, but without any connection with $\left(x_{n}\right)$ more than the spanned space is the same. If $\left(p_{n}\right)$ is a sequence of positive integers let us say that $\left(y_{n}\right)$ is $\left(p_{m}\right)$-ordered in $\left(x_{n}\right)$ if $y_{m} \in \operatorname{span}\left(x_{n}\right)_{n \geq p_{m}}$ with $p_{m+1} \geq p_{m}$ for every $m$, moreover $\lim _{m \rightarrow \infty} p_{m}=\infty$.

Then the following connection is possible.

THEOREM I. For every $\left(x_{n}\right)$ in a Banach space, with $\left[x_{n}\right]$ of infinite dimension, there exists a 1-norming uniformly minimal $M$-basis $\left(z_{n}\right)$ of $\left[x_{n}\right]$, which is $\left(p_{m}\right)$ ordered in $\left(x_{n}\right)$.

This construction is considered in $\S 1$.

(ii) The extension in a given direction: if $\left(x_{n}\right)$ is a uniformly norming $M$-basic sequence of a separable Banach space $B$, is it possible to extend $\left(x_{n}\right)$ to a uniformly minimal norming $M$-basis of $B$ ? In particular is it possible to effect the extension by adding elements of a subspace $Y$ of $B$ which is quasi complementary with $\left[x_{n}\right]$ ?

Received by the editors February 21,1984 and, in revised form, May 15, 1985.

1980 Mathematics Subject Classification (1985 Revision). Primary 46B30. 
The next theorem answers the question:

THEOREM II. For every uniformly minimal norming sequence $\left(x_{n}\right)$ of a separable Banach space $B$ there exists $\left(y_{n}\right)$ so that $\left(x_{n}\right) \cup\left(y_{n}\right)$ becomes a uniformly minimal norming $M$-basis of $B$.

This construction is considered in $\S 2$; we show that in general it is not possible the extension in the direction of a given subspace $Y$ which is quasi complementary to $\left[x_{n}\right]$; but this becomes possible if we only consider norming $M$-basis sequences; that is, if we do not require the uniformly minimal property.

We also consider the nonseparable case and on the way we give another very simple proof of Sobczyk's theorem.

(iii) The construction in given directions: if $X$ and $Y$ are quasi complementary subspaces of a separable Banach space $B$, does there exist a uniformly minimal norming $M$-basis $\left(x_{n}\right) \cup\left(y_{n}\right)$ of $B$, with $\left(x_{n}\right) \subset X$ and $\left(y_{n}\right) \subset Y$ ? In particular, with $\left[x_{n}\right]=X$ and $\left[y_{n}\right]=Y$ ?

The next theorem answers the question:

THEOREM III. For every quasi complementary subspace $X$ and $Y$ of a separable Banach space $B$ there exists a uniformly minimal 1-norming $M$-basis $\left(x_{n}\right) \cup\left(y_{n}\right)$ of $B$, with $\left(x_{n}\right) \subset X$ and $\left(y_{n}\right) \subset Y$.

This construction is considered in $\S 3$; we also see that it is not possible to improve the theorem by setting $\left[x_{n}\right]=X$ or $\left[y_{n}\right]=Y$.

We already studied questions (i) and (ii) in $[\mathbf{1 7}, \mathbf{1 8}$ and 19]; here we only improve and complete these results. Question (iii) is new and expresses the true contribution of the note.

Notations, definitions and recalls. If $U \subseteq B, X$ is subspace of $B, F \subseteq B^{*}$ (the dual of $B$ ) we use the following standard notation: $[U]=\overline{\operatorname{span}}(U), U^{\perp}=\left\{f \in B^{*}\right.$; $f(x)=0$ for every $x$ in $U\}, F_{\perp}=\{x \in B ; f(x)=0$ for every $f$ in $F\}, S(X)=$ the unit sphere of $X=\{x \in X ;\|x\|=1\}$.

We say that $\left(x_{n}\right)$ is complete (or fundamental) in $B$ if $\left[x_{n}\right]=B$.

If $\left(t_{n}\right)$ is an increasing sequence of positive integers and $t_{0}=0$ we say that $\left(y_{n}\right)$ is

(a) a block sequence of $\left(x_{n}\right)$ if $y_{m} \in \operatorname{span}\left(x_{n}\right)_{n=t_{m-1}+1}^{t_{m}}$ for every $m$;

(b) a block perturbation of $\left(x_{n}\right)$ if $\operatorname{span}\left(y_{n}\right)_{n=t_{m-1}+1}^{t_{m}}=\operatorname{span}\left(x_{n}\right)_{n=t_{m-1}+1}^{t_{m}}$ for every $m$. We say that the subspaces $X_{1}, \ldots, X_{m}$ of $B$ are quasi complementary if

$$
\begin{array}{r}
\overline{X_{1}+\cdots+X_{m}}=B, \quad X_{n} \cap \overline{X_{1}+\cdots+X_{n-1}+X_{n+1}+\cdots+X_{m}}=\{0\} \\
\text { for } 1 \leq n \leq m .
\end{array}
$$

Now other standard definitions, which we give by means of elements of $B^{*}$ (in parentheses we recall an intrinsic characterization). If $\left(x_{n}\right) \subset B$ and $\left(f_{n}\right) \subset B^{*}$ we say that

(c) $\left(x_{n}, f_{n}\right)$ is a biorthogonal system if $f_{m}\left(x_{n}\right)=\delta_{m n}$ (Kronecker indices) for every $m$ and $n$ ( $\Leftrightarrow\left(x_{n}\right)$ is minimal, that is $x_{m} \notin\left[x_{n}\right]_{n \neq m}$ for every $\left.m\right)$. If $\left(x_{n}, f_{n}\right)$ is biorthogonal with $\left(x_{n}\right)$ complete in $B$ we say that $\left(x_{n}\right)$ is

(d) K-uniformly minimal where $0<K \leq 1$ if $\sup \left\{\left\|x_{n}\right\| \cdot\left\|f_{n}\right\| ; 1 \leq n<\infty\right\}=$ $1 / K\left(\Leftrightarrow \inf \left\{\operatorname{dist}\left(x_{m} /\left\|x_{m}\right\|,\left[x_{n}\right]_{n \neq m}\right) ; 1 \leq m<\infty\right\}=K\right)$

(e) an $M$-basis of $B$ if $\left[f_{n}\right]$ is total on $B$, that is $\left[f_{n}\right]_{\perp}=\{0\}\left(\Leftrightarrow \bigcap_{m=1}^{\infty}\left[x_{n}\right]_{n \geq m}=\right.$ $\{0\})$; 
(f) a $K$-norming $M$-basis of $B$ if $\left[f_{n}\right]$ is $K$-norming on $B$, where $1 \leq K<$ $\infty$, that is if $\|x\| \leq K \sup \left\{|f(x)| ; f \in S\left(\left[f_{n}\right]\right)\right\}$ for every $x$ in $B(\Leftrightarrow\|x\| \leq$ $K \sup \left\{\operatorname{dist}\left(x,\left[x_{n}\right]_{n \geq m}\right) ; 1 \leq m<\infty\right\}$ for every $x$ in $\left.B\right)$;

(g) a basis of $B$ if $x=\sum_{n=1}^{\infty} f_{n}(x) x_{n}$ for every $x$ in $B$ ( $\Leftrightarrow$ there exists $1 \leq K<\infty$ so that $\left\|\sum_{n=1}^{m} a_{n} x_{n}\right\| \leq K\left\|\sum_{n=1}^{m+p} a_{n} x_{n}\right\|$ for every sequence $\left(a_{n}\right)_{n=1}^{m+p}$ of numbers). About (f) we recall that, if $x \in B$ with $\|x\|=1 \leq K \sup \left\{\operatorname{dist}\left(x,\left[x_{n}\right]_{n \geq m}\right) ; 1 \leq\right.$ $m<\infty\}$, then for every $\varepsilon>0$ there exists a positive integer $m_{\varepsilon}$ and $f_{\varepsilon} \in B^{*}$ so that $f_{\varepsilon}(x)=1,\left\|f_{\varepsilon}\right\|<K+\varepsilon,\left[f_{\varepsilon}\right]_{\perp} \supset\left[x_{n}\right]_{n>m_{\varepsilon}}=\bigcap_{n=1}^{m_{\varepsilon}}\left[f_{n}\right]$, which imply $f_{\varepsilon} \in \operatorname{span}\left(f_{n}\right)_{n=1}^{m_{\varepsilon}}[\mathbf{2 2}$, p. 39, Theorem 3].

We say that $\left(x_{n}\right)$ is $M$-basic (basic) if it is an $M$-basis (basis) of $\left[x_{n}\right]$; we also say that $\left(x_{n}\right)$ is uniformly minimal (norming $M$-basic) if it is $K$-uniformly minimal ( $K$-norming $M$-basic) for some $K$.

In what follows known theorems are enumerated by starred Roman figures. The key to the proof of Ovsepian-Pełczynski theorem is the following property:

$\mathrm{I}^{*}$ [9] (see also [5, p. 44 and 13, pp. 248-250]). If $\left(x_{n}, f_{n}\right)$ is biorthogonal with $\left(\left\|x_{n_{k}}\right\| \cdot\left\|f_{n_{k}}\right\|\right)$ bounded for an infinite subsequence $\left(n_{k}\right)$ of $(n)$, there exist two block perturbations $\left(y_{n}\right)$ and $\left(h_{n}\right)$, of $\left(x_{n}\right)$ and $\left(f_{n}\right)$ respectively, so that $\left(\left\|y_{n}\right\|\left\|h_{n}\right\|\right)$ is bounded and $\left(y_{n}, h_{n}\right)$ is biorthogonal.

About question (ii) of the introduction we recall

$\mathrm{II}^{*}[\mathbf{8}]$ (see also $[18$, p. 172 and 13, p. 860]). If $X$ and $Y$ are quasi complementary subspaces of a separable $B$ and if $\left(x_{n}\right)$ is an $M$-basis of $X$, there exists an $M$-basis $\left(x_{n}\right) \cup\left(y_{n}\right)$ of $B$ with $\left(y_{n}\right) \subset Y$.

It is not possible to improve Theorem $\mathrm{II}^{*}$ by setting $\left[y_{n}\right]=Y[\mathbf{1 2}$, Corollary 3 , p. 186]; however this becomes possible under stronger conditions, indeed:

III* $^{*}$ 12, p. 185, Theorem 3]. Let $X$ and $Y$ be quasi complementary subspaces of a separable $B$ and let $\left(x_{n}\right)$ be an $M$-basis of $X$. Then there exists an $M$-basis $\left(y_{n}\right)$ of $Y$ so that $\left(x_{n}\right) \cup\left(y_{n}\right)$ is an $M$-basis of $B \Leftrightarrow$ there exists $\left(f_{n}\right)$ of $Y^{\perp}$ so that $\left(x_{n}, f_{n}\right)$ is biorthogonal.

About question (iii) of the introduction we recall

$\mathrm{IV}^{*}[\mathbf{2 1}]$ (see also $[\mathbf{1 2}$, p. 187, Corollary 4] or $[\mathbf{1 3}$, p. 235, Corollary 8.4]). If $X$ and $Y$ are quasi complementary subspaces of a separable $B$ there exists an $M$-basis $\left(x_{n}\right) \cup\left(y_{n}\right)$ of $B$ with $\left(x_{n}\right)$ an $M$-basis of $X$ and $\left(y_{n}\right)$ an $M$-basis of $Y$.

Moreover we use the following property of Krasnoselskii, Krein and Milman.

$\mathrm{V}^{*}$ [4] (see also [11, p. 269]). If $U$ and $V$ are finite dimensional subspaces of $B$, with dimension of $V>$ dimension of $U, V$ has an element $x \neq 0$ which is "orthogonal" to $U$, that is $\operatorname{dist}(x, U)=\|x\|$.

2. On the connection of a uniformly minimal norming $M$-basis to a fixed sequence. In this section $B$ is a Banach space, $\left(x_{n}\right)$ is linearly independent sequence in $B, X=\left[x_{n}\right]$. We already proved $[\mathbf{1 7}$, Theorem I] that

$\mathrm{VI}^{*}$. There exists a minimal sequence $\left(y_{n}\right)$ of $B$ which is $(m)$-ordered in $\left(x_{n}\right)$ and complete in $X$.

First we remark that it is not possible to improve Theorem I by setting $p_{m}=m$ for every $m$, as in Theorem $\mathrm{VI}^{*}$; indeed

Proposition 1. If $\left(x_{n}\right)$ is minimal but not $M$-basic there does not exist an $M$-basis $\left(z_{n}\right)$ of $X$ which is $(m)$-ordered in $\left(x_{n}\right)$. 
ProOF. Let $\left(x_{n}, f_{n}\right)$ be biorthogonal, let $\left(z_{n}\right)$ be complete in $X$ and $(m)$-ordered in $\left(x_{n}\right)$. It is sufficient to verify that $f_{m}\left(z_{m}\right) \neq 0$ for every $m$; indeed in this case, setting

$$
g_{1}=\frac{f_{1}}{f_{1}\left(z_{1}\right)}, \quad g_{m}=\frac{1}{f_{m}\left(z_{m}\right)}\left(f_{m}-\sum_{n=1}^{m-1} f_{m}\left(z_{n}\right) g_{n}\right) \quad \text { for } m>1,
$$

it follows that $\left(z_{n}, g_{n}\right)$ is biorthogonal with $\left[g_{n}\right]=\left[f_{n}\right]$, hence $\left(z_{n}\right)$ cannot be an $M$-basis of $X$ if $\left(x_{n}\right)$ is not $M$-basic.

Obviously $f_{1}\left(z_{1}\right) \neq 0$ since otherwise $X=\left[x_{n}\right] \subset\left[x_{n}\right]_{n>2}$, hence suppose that $f_{\bar{m}}\left(z_{\bar{m}}\right)=0$ for $\bar{m}>1$. It would follow that $\left[z_{n}\right]_{n \geq \bar{m}} \subset\left[x_{n}\right]_{n>\bar{m}}$; that is, since $\left[z_{n}\right]=X=\left[x_{n}\right],\left[z_{n}\right]_{n=1}^{\bar{m}-1}+\left[x_{n}\right]_{n>\bar{m}}=X$; while $X /\left[x_{n}\right]_{n>\bar{m}}$ has dimension $\bar{m}$ since $\left(x_{n}\right)$ is minimal. This completes the proof of Proposition 1.

Now we pass to the proof of Theorem I. We shall use the following obvious fact.

$$
\operatorname{dist}\left(v_{1},\left[v_{n}\right]_{n=2}^{m}+W\right)=\operatorname{dist}\left(v_{1}+W,\left[v_{n}+W\right]_{n=2}^{m}\right)
$$

for every $\left(v_{n}\right)_{n=1}^{m}$ of $B$ and for every subspace $W$ of $B$. We need two lemmas.

LEMMA 1. Let $\left(x_{n}\right)$ be minimal and let $\left(\varepsilon_{n}\right)$ be a sequence of numbers with $0<\varepsilon_{n}<1$ for every $n$; then there exist $\left(t_{n}\right) \subseteq(n)$ and a block perturbation $\left(y_{n}\right)$ of $\left(x_{n}\right)$ so that $\left\|y_{t_{m}}\right\|=1$ and $\operatorname{dist}\left(y_{t_{m}},\left[y_{n}\right]_{n \neq t_{m}}\right)>1-\varepsilon_{m}$ for every $m$.

PROOF. We shall proceed by induction.

Let $z_{1} \in S\left(\left[x_{n}\right]_{n=1}^{t_{1}}\right)$ so that $\operatorname{dist}\left(z_{1},\left[x_{n}\right]_{n>1}\right)>1-\varepsilon_{1}$. Hence $\operatorname{dist}\left(z_{1},\left[x_{n}\right]_{n>t_{1}}\right)>$ $1-\varepsilon_{1}$. Fix $p \geq 1$ and suppose we have $\left(z_{m}\right)_{m=1}^{p}$ in $B$ and $\left(t_{m}\right)_{m=0}^{p}$ of increasing natural numbers, with $t_{0}=0$, so that, for $1 \leq m \leq p$,

$$
\begin{aligned}
z_{m} \in S\left(\left[x_{n}\right]_{n=t_{m-1}+1}^{t_{m}}\right), \quad \operatorname{dist}\left(z_{m}, X_{m}\right)>1-\varepsilon_{m} \\
\text { where } X_{m}=\left[x_{n}\right]_{n=1}^{t_{m-1}}+\left[x_{n}\right]_{n>t_{m}} \text { if } m>1 \text { and } X_{1}=\left[x_{n}\right]_{n>t_{1}} .
\end{aligned}
$$

By Theorem $\mathrm{V}^{*}$, in the Banach space $B /\left[x_{n}\right]_{n>2 t_{p}+1}$ there exist $t_{p+1} \geq 2 t_{p}+1$ and $z_{p+1}^{\prime}$, with $z_{p+1}^{\prime}+\left[x_{n}\right]_{n>2 t_{p}+1} \in \operatorname{span}\left(x_{k}+\left[x_{n}\right]_{n>2 t_{p}+1}\right)_{k=t_{p}+1}^{2 t_{p}+1}$, so that

$$
\left\|z_{p+1}^{\prime}+\left[x_{n}\right]_{n>2 t_{p}+1}\right\|=1=\operatorname{dist}\left(z_{p+1}^{\prime}+\left[x_{n}\right]_{n>2 t_{p}+1},\left[x_{k}+\left[x_{n}\right]_{n>2 t_{p}+1}\right]_{k=1}^{t_{p}}\right) ;
$$

$z_{p+1}^{\prime} \in\left[x_{n}\right]_{n=t_{p}+1}^{t_{p+1}},\left\|z_{p+1}^{\prime}\right\|<1 /\left(1-\varepsilon_{p+1}\right)$. Therefore, setting $z_{p+1}=z_{p+1}^{\prime} /\left\|z_{p+1}^{\prime}\right\|$, by (1) and (2) it follows that

$$
\begin{aligned}
\operatorname{dist}\left(z_{p+1}, X_{p+1}\right) & =\frac{1}{\left\|z_{p+1}^{\prime}\right\|} \operatorname{dist}\left(z_{p+1}^{\prime},\left[x_{n}\right]_{n=1}^{t_{p}}+\left[x_{n}\right]_{n>t_{p+1}}\right) \\
& \geq \frac{1}{\left\|z_{p+1}^{\prime}\right\|} \operatorname{dist}\left(z_{p+1}^{\prime},\left[x_{n}\right]_{n=1}^{t_{p}}+\left[x_{n}\right]_{n>2 t_{p}+1}\right) \\
& =\frac{1}{\left\|z_{p+1}^{\prime}\right\|} \operatorname{dist}\left(z_{p+1}^{\prime}+\left[x_{n}\right]_{n>2 t_{p}+1},\left[x_{k}+\left[x_{n}\right]_{n>2 t_{p}+1}\right]_{k=1}^{t_{p}}\right) \\
& =\frac{1}{\left\|z_{p+1}^{\prime}\right\|}>1-\varepsilon_{p+1} ;
\end{aligned}
$$

that is we have $(2)$ for $p+1$ instead of $p$. So proceeding we construct $\left(z_{m}\right)$ and $\left(t_{m}\right)$. 
Fix $m \geq 1$ and consider the quotient space $X / X_{m}$, which by (2) has dimension $t_{m}-t_{m-1}$; there exists $\left(v_{m n}\right)_{n=t_{m-1}+1}^{t_{m}-1}$ such that, by $(2)$,

$$
X / X_{m}=\left[x_{n}+X_{m}\right]_{n=t_{m-1}+1}^{t_{m}}=\left[z_{m}+X_{m}\right]+\left[v_{m n}+X_{m}\right]_{n=t_{m-1}+1}^{t_{m}-1},
$$

with $\left(v_{m n}\right)_{n=t_{m-1}+1}^{t_{m}-1} \subset\left[x_{n}\right]_{n=t_{m-1}+1}^{t_{m}}$ and $\operatorname{dist}\left(z_{m}+X_{m},\left[v_{m n}+X_{m}\right]_{n=t_{m-1}+1}^{t_{m}-1}\right)=$ $\left\|z_{m}+X_{m}\right\| ;$ therefore by (1) and (2)

$$
\operatorname{dist}\left(z_{m},\left[v_{m n}\right]_{n=t_{m-1}+1}^{t_{m}-1}+\left[x_{n}\right]_{n=1}^{t_{m-1}}+\left[x_{n}\right]_{n>t_{m}}\right)>1-\varepsilon_{m} .
$$

It is now sufficient to set, for every $m, y_{t_{m}}=z_{m}, y_{n}=v_{m n}$ for $t_{m-1}+1 \leq n \leq$ $t_{m}-1$. Hence $\operatorname{dist}\left(y_{t_{m}},\left[y_{n}\right]_{n \neq t_{m}}\right)>1-\varepsilon_{m}$. This completes the proof of Lemma 1 .

LEMMA 2. There exists a 1-norming $M$-basis $\left(z_{n}\right)$ of $X$ which is $\left(p_{m}\right)$-ordered in $\left(x_{n}\right)$, with $p_{m} \geq m / 2$ for every $m$.

Proof. By Theorem VI* we can suppose $\left(x_{n}\right)$ minimal; moreover, since to be norming is an intrinsic property of a sequence (see (f) in notation section) we can suppose $X=B$; therefore there exists $\left(f_{n}\right) \cup\left(l_{n}\right) \subset B^{*}$ so that

$$
\left(x_{n}, f_{n}\right) \text { is biorthogonal, }\left[\left(f_{n}\right) \cup\left(l_{n}\right)\right] \text { is 1-norming on } B=\left[x_{n}\right] \text {. }
$$

We proceed by induction. Set $z_{n}^{\prime}=x_{n}$ and $g_{n}=f_{n}$ for $1 \leq n \leq 3$; if $l_{1} \in\left[g_{n}\right]_{n=1}^{3}$ we consider $l_{2}$, otherwise $\left[\left(g_{n}\right)_{n=1}^{3}\right]_{\perp} \not \subset\left[l_{1}\right]_{\perp}[\mathbf{2 2}$, p. 39, Theorem 3]. Hence there exists $z_{4}^{\prime}$ of $\left[\left(g_{n}\right)_{n=1}^{3}\right]_{\perp}$ with $l_{1}\left(z_{4}^{\prime}\right)=1$; we set

$$
g_{4}=l_{1}-\sum_{n=1}^{3} l_{1}\left(z_{n}^{\prime}\right) g_{n}
$$

Fix $m \geq 1$ and suppose that $\left(z_{n}^{\prime}\right)_{n=1}^{4 m}$ is in $B$ and $\left(g_{n}\right)_{n=1}^{4 m}$ is in $B^{*}$ so that

$$
\begin{aligned}
& \left(z_{n}^{\prime}, g_{n}\right)_{n=1}^{4 m} \text { is biorthogonal, } \\
& \left(x_{n}\right)_{n=1}^{m} \subset\left[z_{n}^{\prime}\right]_{n=1}^{4 m}, \quad\left(f_{n}\right)_{n=1}^{2 m} \cup\left(l_{n}\right)_{n=1}^{m} \subset\left[g_{n}\right]_{n=1}^{4 m} .
\end{aligned}
$$

If $f_{2 m+1} \in\left[g_{n}\right]_{n=1}^{4 m}$ we consider $f_{2 m+2}$; otherwise $\left[\left(g_{n}\right)_{n=1}^{4 m}\right]_{\perp} \not \subset\left[f_{2 m+1}\right]_{\perp}$. Hence there exists $z_{4 m+1}^{\prime} \in\left[\left(g_{n}\right)_{n=1}^{4 m}\right]_{\perp}$ with $f_{2 m+1}\left(z_{4 m+1}^{\prime}\right)=1$. Then we set

$$
g_{4 m+1}=f_{2 m+1}-\sum_{n=1}^{4 m} f_{2 m+1}\left(z_{n}^{\prime}\right) g_{n}
$$

We proceed in the same way for $f_{2 m+2}$ and $l_{m+1}$, getting $z_{4 m+2}^{\prime}, z_{4 m+3}^{\prime}, g_{4 m+2}$, $g_{4 m+3}$. If $x_{m+1} \in\left[z_{n}^{\prime}\right]_{n=1}^{4 m+3}$ we consider $x_{m+2}$; otherwise $\left[\left(z_{n}^{\prime}\right)_{n=1}^{4 m+3}\right]^{\perp} \not \subset\left[x_{m+1}\right]^{\perp}$. Hence there exists $g_{4(m+1)} \in\left[\left(z_{n}^{\prime}\right)_{n=1}^{4 m+3}\right]^{\perp}$ with $g_{4(m+1)}\left(x_{m+1}\right)=1$. We set

$$
z_{4(m+1)}^{\prime}=x_{m+1}-\sum_{n=1}^{4 m+3} g_{n}\left(x_{m+1}\right) z_{n}^{\prime} ;
$$

that is we have (4) for $m+1$ instead of $m$.

So proceeding we construct $\left(z_{n}^{\prime}\right)$ and $\left(g_{n}\right)$ with $\left(z_{n}^{\prime}, g_{n}\right)$ biorthogonal, so that (4) is true for every $m$; hence by $(3)\left(z_{n}^{\prime}\right)$ is a 1 -norming $M$-basis of $X$. It is known (see for example $\left[16\right.$, p. 175, Theorem X]) that there exist positive numbers $\left(\varepsilon_{n}\right)$ 
so that

$$
\begin{aligned}
& \left(z_{n}\right) \subset X \text { with }\left\|z_{n}-z_{n}^{\prime}\right\|<\varepsilon_{n} \text { for every } n \\
& \text { imply that }\left(z_{n}\right) \text { is a } 1 \text {-norming } M \text {-basis of } X .
\end{aligned}
$$

Now $\left(z_{n}^{\prime}\right) \subset\left[x_{n}\right]$ and by (4) $f_{m}\left(z_{n}^{\prime}\right)=0$ for $n>2 m$ for every $m$; therefore there exists $\left(z_{n}\right)$ with $z_{m} \in \operatorname{span}\left(x_{n}\right)_{n \geq m / 2}$ and $\left\|z_{m}-z_{m}^{\prime}\right\|<\varepsilon_{m}$ for every $m$; that is $\left(z_{n}\right)$ is $\left(p_{m}\right)$-ordered in $\left(x_{n}\right)$ with $p_{m} \geq m / 2$ for every $m$. The proof of Lemma 2 is complete.

PROOF OF THEOREM I. By Lemma 2 we can suppose $\left(x_{n}\right)$ is 1 -norming $M$ basic. By Lemma 1 there exist an increasing sequence $\left(t_{n}\right)$ of positive integers, $\left(h_{n}\right)$ in $B^{*}$ and a block perturbation $\left(y_{n}\right)$ of $\left(x_{n}\right)$ so that $\left(y_{n}, h_{n}\right)$ is biorthogonal, with $\left\|y_{t_{n}}\right\|=1$ and $\left\|h_{t_{n}}\right\|<2$ for every $n$. Finally by Theorem $\mathrm{I}^{*}$ there exists a block perturbation $\left(z_{n}\right)$ of $\left(y_{n}\right)$ which is uniformly minimal; obviously $\left(z_{n}\right)$ is still a 1-norming $M$-basis of $X$ since it is a block perturbation of a block perturbation of $\left(x_{n}\right)$, hence it is also $\left(p_{m}\right)$-ordered in $\left(x_{n}\right)$. The proof of Theorem $\mathrm{I}$ is complete.

2. On the extension of uniformly minimal norming $M$-bases. In this section $B$ is a Banach space and $\left(x_{n}\right)$ is a sequence in $B$ with $\left[x_{n}\right]=X$. First we consider the nonseparable case, where the problem of the extension does not have a positive answer; indeed:

PROPOSITION 2. If $\left(x_{n}\right)$ is a uniformly minimal sequence of $B$ in general there is no $\left(f_{n}\right)$ in $B^{*}$ such that $\left(x_{n}, f_{n}\right)$ is biorthogonal, $\left(\left\|x_{n}\right\|\left\|f_{n}\right\|\right)$ is bounded, $\left[x_{n}\right]+$ $\left[f_{n}\right]_{\perp}$ is dense in $B$.

PROOF. Suppose $\left(x_{n}\right)$ and $\left(f_{n}\right)$ are as in the proposition, in the particular case of $X=c_{0}$ with $\left(x_{n}\right)$ the natural basis of $c_{0}$. Then it follows that $c_{0}$ is complemented in $B$, since $\operatorname{dist}\left(S(X),\left[f_{n}\right]_{\perp}\right) \geq 1 / K$ where $\left\|x_{n}\right\| \cdot\left\|f_{n}\right\| \leq K<\infty$ for every $n$. Now it is known that $c_{0}$ is not complemented in every Banach space (see for example [23, pp. 146 and 237]).

REMARK. Recall that Sobczyk's theorem states ([14]; see also $[\mathbf{2 0}]$; or $[\mathbf{5}, \mathrm{p}$. 106, Theorem 2.F.5]; or [23, p. 146]) that $c_{0}$ is complemented in every separable Banach space, with a projection of norm $\leq 2$; moreover this property characterizes $c_{0}$ among the separable Banach spaces [24]. Another simple proof of Sobczyk's theorem is as follows: Suppose $X=c_{0}$ with the natural basis $\left(x_{n}\right)$ and $B$ separable. By Corollary 1 of $[19]$ there exists for every $\varepsilon>0$ a sequence $\left(f_{n}\right)$ of $B^{*}$ such that $\left(x_{n}, f_{n}\right)$ is biorthogonal and $\left[x_{n}\right]+\left[f_{n}\right]_{\perp}$ is dense in $B$, with $\left\|f_{n}\right\|<2+\varepsilon$ for every $n$; it follows that $\operatorname{dist}\left(S(X),\left[f_{n}\right]_{\perp}\right)>1 /(2+\varepsilon)$.

We now consider the separable case.

About the extension in a given direction we already proved [19, Example] that this is not possible for a uniformly minimal sequence; that is, it is not possible to improve Theorem II by extending Theorem II*. However this becomes possible for the norming property only. Indeed,

PROPOSITION 3. If $X$ and $Y$ are quasi complementary subspaces of a separable $B$ and if $\left(x_{n}\right)$ is a $K$-norming $M$-basis of $X$ there exists $\left(y_{n}\right)$ in $Y$ such that $\left(x_{n}\right) \cup\left(y_{n}\right)$ becomes an $H$-norming $M$-basis of $B$, with $H \leq 4 K$.

We now prove Proposition 3 and Theorem II. We need three lemmas.

LEMMA 3. If $\left(y_{n}\right)_{n=1}^{p} \cup\left(x_{n}\right)$ is minimal with $1 \leq p<\infty$ and with $\left(x_{n}\right) K$ norming, then $\left(y_{n}\right)_{n=1}^{p} \cup\left(x_{n}\right)$ is $H$-norming with $H \leq 4 K$. 
PROOF. If not there exist $\bar{x}$ of $S\left(\left[y_{n}\right]_{n=1}^{p}+\left[x_{n}\right]\right), \bar{a}>0$, and a block sequence $\left(w_{n}\right)$ of $\left(x_{n}\right)$ so that, for every $n, 4(K+\bar{a})\left\|w_{n}-\bar{x}\right\|<1$; hence, setting $v_{n}=w_{n} /\left\|w_{n}\right\|$, we have that

$$
\left\|v_{n}-w_{n}\right\|=\left|1-\left\|w_{n}\right\|\right|=\left|\|\bar{x}\|-\left\|w_{n}\right\|\right| \leq\left\|\bar{x}-w_{n}\right\| ;
$$

that is

$$
(K+\bar{a})\left\|\bar{x}-v_{n}\right\| \leq(K+\bar{a})\left\|\bar{x}-w_{n}\right\|+(K+\bar{a})\left\|w_{n}-v_{n}\right\| \leq 2(K+\bar{a})\left\|\bar{x}-w_{n}\right\|<1 / 2 .
$$

Therefore, for every $m$ and $n$,

$$
(K+\bar{a})\left\|v_{n}-v_{n+m}\right\| \leq(K+\bar{a})\left\|\bar{x}-v_{n}\right\|+(K+\bar{a})\left\|\bar{x}-v_{n+m}\right\|<1=\left\|v_{n}\right\| .
$$

But this is impossible by hypothesis, since $\left(x_{n}\right)$ is $K$-norming (see (f) in definitions section) which completes the proof of Lemma 3.

LEMMA 4. Let $X$ and $Y$ be quasi complementary subspaces of $B$ with $\left(x_{n}, f_{n}\right)$ biorthogonal and $Y \subseteq\left[f_{n}\right]_{\perp}$, and let $\left(x_{n}\right)_{n>r} \subset\left[\left(g_{n}\right)_{n=1}^{q}\right]_{\perp}$ where $\left(g_{n}\right)_{n=1}^{q} \subset B^{*}$ and $r, q$ are positive integers. Then there exist $\left(y_{n}\right)_{n=1}^{p} \subset Y$ and $\left(h_{n}\right)_{n=1}^{p} \subset B^{*}$ so that $\left(x_{n}, f_{n}\right) \cup\left(y_{n}, h_{n}\right)_{n=1}^{p}$ is biorthogonal, with $\left(g_{n}\right)_{n=1}^{q} \subset \operatorname{span}\left(f_{n}\right)_{n=1}^{r}+\operatorname{span}\left(h_{n}\right)_{n=1}^{p}$.

PROOF. Fix $1 \leq \bar{m} \leq q$.

If we consider the restrictions of the functionals to $X$, since $\left(x_{n}\right)_{n>r} \subset\left[g_{\bar{m}}\right]_{\perp}$, we have that

$$
\left[\left(\left.f_{n}\right|_{X}\right)_{n=1}^{r}\right]_{\perp}=\left[x_{n}\right]_{n>r} \subset\left[\left.g_{\bar{m}}\right|_{X}\right]_{\perp}
$$

hence $\left.g_{\bar{m}}\right|_{X} \in \operatorname{span}\left(\left.f_{n}\right|_{X}\right)_{n=1}^{r}$, that is, $g_{\bar{m}}=g_{\bar{m}}^{\prime}+g_{\bar{m}}^{\prime \prime}$ with $g_{\bar{m}}^{\prime} \in\left[f_{n}\right]_{n=1}^{r}$ and $g_{\bar{m}}^{\prime \prime} \in X^{\perp}$. So if $\left(h_{n}\right)_{n=1}^{p}$ is an algebraic basis of $\operatorname{span}\left(g_{n}^{\prime \prime}\right)_{n=1}^{q}$, we have that

$$
\left(g_{n}\right)_{n=1}^{q} \subset \operatorname{span}\left(f_{n}\right)_{n=1}^{r}+\operatorname{span}\left(h_{n}\right)_{n=1}^{p}, \quad \text { with }\left(h_{n}\right)_{n=1}^{p} \subset X^{\perp} .
$$

Fix $1 \leq \bar{n} \leq p$. Since $\left(h_{n}\right)_{n=1}^{p}$ is linearly independent in $X^{\perp}$ and $\overline{X+Y}=B$, we have that

$$
\left.h_{\bar{n}}\right|_{Y} \notin \operatorname{span}\left(\left.h_{n}\right|_{Y}\right)_{n=1, n \neq \bar{n}}^{p} ; \text { that is }\left[\left.h_{\bar{n}}\right|_{Y}\right]_{\perp} \not \supset\left[\left(\left.h_{n}\right|_{Y}\right)_{n=1, n \neq \bar{n}}^{p}\right]_{\perp},
$$

hence there exists $y_{\bar{n}} \in Y$ so that $h_{\bar{n}}\left(y_{\bar{n}}\right)=1, y_{\bar{n}} \in\left[\left(h_{n}\right)_{n=1, n \neq \bar{n}}^{p}\right]_{\perp}$. We pick $\left(y_{n}\right)_{n=1}^{p}$ which completes the proof of Lemma 4 .

LEMMA 5. If $X$ and $Y$ are quasi complementary subspaces of a separable $B$ and if $\left(x_{n}\right)$ is a $K$-norming $M$-basis of $X$ with $\left(x_{n}, f_{n}\right)$ biorthogonal and $Y \subseteq\left[f_{n}\right]_{\perp}$, there exists an $H$-norming $M$-basis $\left(x_{n}\right) \cup\left(y_{n}\right)$ of $B$ with $H \leq 4 K$ and $\left[y_{n}\right]=Y$.

Proof. Let $\left(\bar{v}_{n}\right)$ be a sequence complete in $Y$. Fix an integer $m>1$ and suppose we have an increasing sequence of integers $\left(p_{n}\right)_{n=1}^{m-1}$, with $p_{1}=1$, an integer $p_{m}^{\prime} \geq p_{m-1}$ and two sequences $\left(y_{n}\right)_{n=1}^{p_{m}^{\prime}},\left(h_{n}\right)_{n=1}^{p_{m}^{\prime}}$ so that

$$
\begin{aligned}
& \left(x_{n}, f_{n}\right) \cup\left(y_{n}, h_{n}\right)_{n=1}^{p_{m}^{\prime}} \text { is biorthogonal with }\left(y_{n}\right)_{n=1}^{p_{m}^{\prime}} \subset Y ; \\
& \operatorname{dist}\left(\bar{v}_{n},\left[y_{k}\right]_{k=1}^{p_{m-1}}\right)<1 / 2^{m-1} \text { for } 1 \leq n \leq m-1 ; \\
& {\left[f_{n}, h_{n}\right]_{n=1}^{p_{m}^{\prime}} \text { is }\left(4 K+1 / 2^{m-1}\right) \text {-norming on }\left[x_{n}, y_{n}\right]_{n=1}^{p_{m-1}} .}
\end{aligned}
$$

The thesis will be proved if for (5) it is possible to proceed by induction; that is, it is possible to have (5) for $m=2$, moreover it is possible in (5) to pass from the general $m$ to $m+1$. We can describe the induction by only one step, since the 
construction of (5) for $m=2$ becomes a particular case of the general procedure, if we use the convention that for $m=1$ we mean the initial situation, where the sequences $\left(y_{n}\right)_{n=1}^{p_{m}^{\prime}}$ and $\left(h_{n}\right)_{n=1}^{p_{m}^{\prime}}$ do not appear.

We now prove the existence of (5) for $m+1$ instead of $m$. By (5) $Y=\left[y_{n}\right]_{n=1}^{p_{m}^{\prime}}+$ $Y \cap\left[\left(h_{n}\right)_{n=1}^{p_{m}^{\prime}}\right]_{\perp}$; hence by Theorem III* and by hypothesis there exist $\left(y_{n}\right)_{n=p_{m}^{\prime}+1}^{p_{m}}$ in $Y \cap\left[\left(h_{n}\right)_{n=1}^{p_{m}^{\prime}}\right]_{\perp}$ and $\left(h_{n}\right)_{n=p_{m}^{\prime}+1}^{p_{m}}$ in $B^{*}$ so that $\left(x_{n}, f_{n}\right) \cup\left(y_{n}, h_{n}\right)_{n=1}^{p_{m}}$ is biorthogonal, $\operatorname{dist}\left(\bar{v}_{n},\left[y_{k}\right]_{k=1}^{p_{m}}\right)<1 / 2^{m}$ for $1 \leq n \leq m$. By Lemma $3\left(y_{n}\right)_{n=1}^{p_{m}} \cup\left(x_{n}\right)$ is $K_{m}$-norming, with $K_{m} \leq 4 K$; hence there exist a finite sequence $\left(g_{m n}\right)_{n=1}^{s_{m}}$ of $B^{*}$ and a positive integer $r_{m}$ so that $\left[g_{m n}\right]_{n=1}^{s_{m}}$ is $\left(4 K+1 / 2^{m}\right)$-norming on $\left[x_{n}, y_{n}\right]_{n=1}^{p_{m}}$, with $\left(x_{n}\right)_{n>r_{m}} \subset\left[\left(g_{m n}\right)_{n=1}^{s_{m}}\right]_{\perp}$. By Lemma 4 there exist an integer $p_{m+1}^{\prime} \geq \max \left\{p_{m}, r_{m}\right\}$, a sequence $\left(y_{n}\right)_{n=p_{m}+1}^{p_{m+1}^{\prime}}$ in $Y \cap\left[\left(h_{n}\right)_{n=1}^{p_{m}}\right]_{\perp}$ and $\left(h_{n}\right)_{n=p_{m}+1}^{p_{m+1}^{\prime}}$ in $B^{*}$, so that $\left(x_{n}, f_{n}\right) \cup\left(y_{n}, h_{n}\right)_{n=1}^{p_{m+1}^{\prime}}$ is biorthogonal, $\left(g_{m n}\right)_{n=1}^{s_{m}} \subset \operatorname{span}\left(f_{n}, h_{n}\right)_{n=1}^{p_{m+1}^{\prime}}$. That is, we have (5) for $m+1$ instead of $m$, which completes the proof of Lemma 5 .

Proof of Proposition 3. By Theorem II* there exists $\left(f_{n}\right)$ of $B^{*}$ such that $\left(x_{n}, f_{n}\right)$ is biorthogonal, $\overline{X+Y \cap\left[f_{n}\right]_{\perp}}=B$. Now it is sufficient to use Lemma 5 , for $Y \cap\left[f_{n}\right]_{\perp}$ instead of $Y$.

For the proof of the next lemma we follow the procedure of the proof of Lemma 2 of $[19]$.

LEMMA 6. If $\left(x_{n}, f_{n}\right) \cup\left(u_{n}, g_{n}\right)$ is biorthogonal, with $\left(\left\|x_{n}\right\| \cdot\left\|f_{n}\right\|\right)$ bounded, there exist $\left(z_{n}\right)$ in $B$ so that $\left(x_{n}\right) \cup\left(z_{n}\right)$ is uniformly minimal with $z_{n}=v_{n}+w_{n}$ for every $n$, where $\left(v_{n}\right)$ is a block sequence of $\left(x_{n}\right)$ and $\left(w_{n}\right)$ is a block sequence of $\left(u_{n}\right)$.

Proof of THEOREM II. By hypothesis $\left(x_{n}\right)$ is a $K$-norming $M$-basis of $X$, for $1 \leq K<\infty$; we suppose $\left(x_{n}\right) \subset S(X)$. Since $\left(x_{n}\right)$ is uniformly minimal, by Corollary 1 of $[\mathbf{1 9}]$ there exists $\left(\tilde{f}_{n}\right)$ so that $\left(x_{n}, \tilde{f}_{n}\right)$ is biorthogonal with $\left(\tilde{f}_{n}\right)$ bounded and $X+\left[\tilde{f}_{n}\right]_{\perp}$ dense in $B$. By Proposition 3 there exists $\left(\tilde{z}_{n}\right)$ so that $\left(x_{n}\right) \cup\left(\tilde{z}_{n}\right)$ is an $H^{\prime}$-norming $M$-basis of $B$, with $H^{\prime} \leq 4 K$ and $\left(\tilde{z}_{n}\right) \subset\left[\tilde{f}_{n}\right]_{\perp}$. By Lemma 6 there exists $\left(z_{n}\right)$ of $B$ such that $\left(x_{n}\right) \cup\left(z_{n}\right)$ is uniformly minimal, $\left\|z_{n}\right\|=1$ and $z_{n}=v_{n}+w_{n}$ for every $n$, where $\left(v_{n}\right)$ is a block sequence of $\left(x_{n}\right)$ and $\left(w_{n}\right)$ is a block sequence of $\left(\tilde{z}_{n}\right)$. We point out that $\left(x_{n}\right) \cup\left(z_{n}\right)$ is a block perturbation of a permutation of $\left(x_{n}\right) \cup\left(w_{n}\right)$, which is a block sequence of $\left(x_{n}\right) \cup\left(\tilde{z}_{n}\right)$; hence $\left(x_{n}\right) \cup\left(z_{n}\right)$ is $H^{\prime \prime}$-norming $M$-basic, with $H^{\prime \prime} \leq H^{\prime}$. Again we use Corollary 1 of [19] and there exists $\left(f_{n}\right) \cup\left(g_{n}\right)$ of $B^{*}$ such that $\left(x_{n}, f_{n}\right) \cup\left(z_{n}, g_{n}\right)$ is biorthogonal, $\left(f_{n}\right) \cup\left(g_{n}\right)$ is bounded, $\left[x_{n}\right]+\left[z_{n}\right]+\left[\left(f_{n}\right) \cup\left(g_{n}\right)\right]_{\perp}$ is dense in $B$.

Since $\left(x_{n}\right) \cup\left(z_{n}\right)$ is $H^{\prime \prime}$-norming $M$-basic, by Proposition 3 there exist $\left(\tilde{y}_{n}\right)$ and $\left(\tilde{h}_{n}\right)$ so that $\left(x_{n}\right) \cup\left(z_{n}\right) \cup\left(\tilde{y}_{n}\right)$ is an $H$-norming $M$-basis of $B$, with $H \leq 16 K$; $\left(x_{n}, f_{n}\right) \cup\left(z_{n}, g_{n}\right) \cup\left(\tilde{y}_{n}, \tilde{h}_{n}\right)$ is biorthogonal. Finally by Theorem $\mathrm{I}^{*}$ there exist two block perturbations $\left(y_{n}\right)$ of $\left(z_{n}\right) \cup\left(\tilde{y}_{n}\right)$ and $\left(h_{n}\right)$ of $\left(g_{n}\right) \cup\left(\tilde{h}_{n}\right)$ so that $\left(y_{n}, h_{n}\right)$ is biorthogonal, with $\left(\left\|y_{n}\right\| \cdot\left\|h_{n}\right\|\right)$ bounded. That is, $\left(x_{n}\right) \cup\left(y_{n}\right)$ is a uniformly minimal $H$-norming $M$-basis of $B$, which completes the proof of Theorem II.

3. On the construction of uniformly minimal norming $M$-bases in given directions. In this section $X$ and $Y$ are quasi complementary subspaces of a separable Banach space $B$. First some considerations and secondary properties. 
REMARK. About the extension of Theorem III to the decomposition of $B$ into a finite arbitrary number of quasi complementary subspaces we warn that, if $X$ and $Y$ are quasi complementary subspaces of $B$ and if $X_{1}, X_{2}$ are quasi complementary subspaces of $X$, this does not imply that $X_{1}, X_{2}$ and $Y$ are quasi complementary subspaces of $B$, since it may be that $X_{1} \subset \overline{X_{2}+Y}[\mathbf{1 5}, \mathrm{p}$. 52, Theorem VI].

We already proved for uniformly minimal sequences $[\mathbf{1 9}$, Example] that it is not possible to improve Theorem III by setting $\left[x_{n}\right]=X$ or $\left[y_{n}\right]=Y$. However, for the norming property only there is a sufficient condition, analogous to Theorem III*.

PROPOSITION 4. The following conditions are equivalent:

(i) there exists a norming $M$-basis $\left(x_{n}\right)$ of $X$ with $\left(x_{n}, f_{n}\right)$ biorthogonal and $Y \subset\left[f_{n}\right]_{\perp}$;

(ii) there exists a norming $M$-basis $\left(x_{n}\right) \cup\left(y_{n}\right)$ of $B$ with $\left[x_{n}\right]=X$ and $\left[y_{n}\right]=Y$.

This proposition follows from Lemma 5 of $\S 2$.

Moreover, if we come back to Theorem $\mathrm{V}^{*}$, it is well known that the theorem becomes false if $U$ and $V$ have infinite dimension (see for example [11, pp. 271$272])$; let us strengthen this fact.

PROPOSITION 5. There exists a separable Banach space $B_{0}$ with the following property: for every $\varepsilon>0$ there are two quasi complementary infinite dimensional subspaces $X$ and $Y$ so that $\operatorname{dist}(y, X)<\varepsilon$ for every $y$ in $S(Y)$.

In what follows, if $U$ and $V$ are subsets of $B$, we use the notation

$$
\operatorname{dist}(U, V)=\inf \{\|u+v\| ; u \in U \text { and } v \in V\} .
$$

LEMMA 7. Let $U, V, W$ be quasi complementary subspaces of $B$, with $U$ finite and $\operatorname{dist}(S(V), S(W))=0$; let $\left(\varepsilon_{n}\right)$ be a sequence of numbers with $0<\varepsilon_{n}<1$ for every $n$. Then there exist $\left(m_{k}\right) \subseteq(n),\left(v_{n}\right) \subset S(V)$ and $\left(w_{n}\right) \subset S(W)$ so that $\left(v_{n}\right) \cup\left(w_{n}\right)$ is minimal and complete in $\overline{V+W},\left\|v_{m_{n}}+w_{m_{n}}\right\|<\varepsilon_{n}$ and $\operatorname{dist}\left(v_{m_{n}}, U+\left[\left(v_{k}\right) \cup\left(w_{k}\right)\right]_{k \neq m_{n}}\right)=1$ for every $n$.

PROOF. Let $\left(\bar{x}_{n}\right)$ be a sequence complete in $\overline{V+W}$.

Fix an integer $p>1$ and suppose we have increasing integers $\left(m_{n}\right)_{n=1}^{p}$ with $m_{1}=1,\left(v_{n}, w_{n}\right)_{n=1}^{m_{p}-1}$ of $B$ and $\left(f_{n}, h_{n}\right)_{n=1}^{m_{p}-1} \cup\left(g_{n}\right)_{n=1}^{p-1}$ of $B^{*}$, so that

$$
\begin{aligned}
& \left(v_{n}, f_{n}\right)_{n=1}^{m_{p}-1} \cup\left(w_{n}, h_{n}\right)_{n=1}^{m_{p}-1} \text { is biorthogonal, with }\left(v_{n}\right)_{n=1}^{m_{p}-1} \subset S(V), \\
& \left(w_{n}\right)_{n=1}^{m_{p}-1} \subset S(W) \text { and } U \subset\left[\left(f_{n}, h_{n}\right)_{n=1}^{m_{p}-1}\right]_{\perp} ; \\
& \operatorname{dist}\left(\bar{x}_{n}, U+\left[v_{k}, w_{k}\right]_{k=1}^{m_{p}-1}<1 / 2^{p-1}, \quad\left\|v_{m_{n}}+w_{m_{n}}\right\|<\varepsilon_{n},\right. \\
& g_{n}\left(v_{m_{n}}\right)=\left\|g_{n}\right\|=1 \text { and } g_{n} \in\left[f_{m_{n}}, h_{m_{n}}\right] \quad \text { for } 1 \leq n \leq p-1 ; \\
& U_{p}+\overline{V_{p}+W_{p}}=B, \quad \text { where } U_{p}=U+\left[v_{n}, w_{n}\right]_{n=1}^{m_{p}-1}, \\
& V_{p}=V \cap\left[\left(f_{n}, h_{n}\right)_{n=1}^{m_{p}-1}\right]_{\perp} \quad \text { and } \quad W_{p}=V \cap\left[\left(f_{n}, h_{n}\right)_{n=1}^{m_{p}-1}\right]_{\perp} .
\end{aligned}
$$

Set

$$
\bar{n}_{p}=\text { dimension of } U_{p}+1=\text { dimension of } U+2 m_{p}-1 \text {. }
$$

The thesis will be proved if for (6) it is possible to proceed by induction; that is, if it is possible to have (6) for $p=2$, and, more generally, for $p+1$. We can describe the induction by only one step, since the construction of (6) for $p=2$ becomes a 
particular case of the general procedure if we use the convention that for $p=1$ we mean the initial situation, where the sequences $\left(v_{n}, w_{n}\right)_{n=1}^{m_{p}-1},\left(f_{n}, h_{n}\right)_{n=1}^{m_{p}-1},\left(g_{n}\right)_{n=1}^{p-1}$ do not appear; hence in (6) and in (7) $U_{1}=U, V_{1}=V, W_{1}=W$ and $\bar{n}_{1}=$ dimension of $U+1$.

We now prove the existence of $(6)$ for $p+1$ instead of $p$. We claim that there exist $v_{m_{p}}, w_{m_{p}}$ of $B$ and $g_{p}$ of $B^{*}$ so that

$$
\begin{aligned}
& v_{m_{p}} \in S\left(V_{p}\right), \quad w_{m_{p}} \in S\left(W_{p}\right), \quad\left\|v_{m_{p}}+w_{m_{p}}\right\|<\varepsilon_{p}, \\
& g_{p}\left(v_{m_{p}}\right)=1=\left\|g_{p}\right\|, \quad U_{p}<\left[g_{p}\right]_{\perp} .
\end{aligned}
$$

By hypothesis there exist $\left(z_{p n}\right)_{n=1}^{\bar{n}_{p}}$ of $B$ and $\left(l_{p n}\right)_{n=1}^{\bar{n}_{p}}$ of $B^{*}$ so that

$$
z_{p 1} \in S\left(V_{p}\right) \text { and } z_{p n} \in S\left(V_{p} \cap\left[\left(l_{p k}\right)_{k=1}^{n-1}\right]_{\perp}\right) \quad \text { for } 1<n \leq \bar{n}_{p}
$$

where $l_{p n}\left(z_{p n}\right)=1=\left\|l_{p n}\right\|$ and $\operatorname{dist}\left(z_{p n}, W_{p}\right)<\varepsilon_{p} /\left(\bar{n}_{p} 2^{n+1}\right)$ for $1 \leq n \leq \bar{n}_{p}$.

By (7), (9) and by Theorem $\mathrm{V}^{*}$ there exist $v_{m_{p}}$ and $g_{p}$ so that

$$
v_{m_{p}}=\sum_{n=1}^{\bar{n}_{p}} a_{p n} z_{p n} \in S(B), \quad g_{p}\left(v_{m_{p}}\right)=\left\|g_{p}\right\|=1, \quad U_{p} \subset\left[g_{p}\right]_{\perp} .
$$

We are going to prove that $\operatorname{dist}\left(v_{m_{p}}, W_{p}\right)<\varepsilon_{p} / 4$; then we set

$$
g_{p 1}=l_{p 1} \quad \text { and } \quad g_{p n}=l_{p n}-\sum_{k=1}^{n-1} l_{p n}\left(z_{p k}\right) g_{p k} \quad \text { for } 1<n \leq \bar{n}_{p} ;
$$

by (9) $\left(z_{p n}, g_{p n}\right)_{n=1}^{\bar{n}_{p}}$ is biorthogonal, with $\left\|g_{p 1}\right\|=\left\|l_{p 1}\right\|=1$ and $\left\|g_{p n}\right\| \leq 1+$ $\sum_{k=1}^{n-1}\left\|g_{p k}\right\|$ for $1<n \leq \bar{n}_{p}$; hence $\left\|g_{p n}\right\| \leq 2^{n-1}$ for $1 \leq n \leq \bar{n}_{p}$ since this is true for $n=1$, after by induction $\left\|g_{p n}\right\| \leq 1+\sum_{k=1}^{n-1} 2^{k-1}=2^{n-1}$. Therefore by (10)

$$
\left|a_{p n}\right|=\left|g_{p n}\left(v_{m_{p}}\right)\right| \leq\left\|g_{p n}\right\| \leq 2^{n-1} \text { for } 1 \leq n \leq \bar{n}_{p} ;
$$

that is, by (9) and (10),

$$
\operatorname{dist}\left(v_{m_{p}}, W_{p}\right) \leq \sum_{n=1}^{\bar{n}_{p}}\left|a_{p n}\right| \operatorname{dist}\left(z_{p n}, W_{p}\right)<\frac{\varepsilon_{p}}{4} .
$$

This means that there exists $w_{m_{p}}$ in $S\left(W_{p}\right)$ such that, by (10), we have (8). By (8) and by hypothesis we point out that

$$
\left|g_{p}\left(w_{m_{p}}\right)\right|>1-\varepsilon_{p}>0 .
$$

We claim that there exist $f_{m_{p}}, h_{m_{p}}$ in $B^{*}$ so that

$\left(v_{m_{p}}, f_{m_{p}}\right) \cup\left(w_{m_{p}}, h_{m_{p}}\right)$ is biorthogonal with $g_{p} \in \operatorname{span}\left(f_{m_{p}}, h_{m_{p}}\right)$ and $U_{p} \subset\left[f_{m_{p}}, h_{m_{p}}\right]_{\perp}$; moreover $\left[v_{m_{p}}, w_{m_{p}}\right]+V_{p} \cap\left[f_{m_{p}}, h_{m_{p}}\right]_{\perp}+$ $W_{p} \cap\left[f_{m_{p}}, h_{m_{p}}\right]_{\perp}$ is dense in $\overline{V_{p}+W_{p}}$.

It is sufficient to prove that there exists $h_{m_{p}}$ of $B^{*}$ so that

$$
\begin{aligned}
& h_{m_{p}}\left(w_{m_{p}}\right)=1, \quad\left[v_{m_{p}}\right]+U_{p} \subset\left[h_{m_{p}}\right]_{\perp}, \\
& {\left[v_{m_{p}}, w_{m_{p}}\right]+V_{p} \cap\left[g_{p}, h_{m_{p}}\right]_{\perp}+W_{p} \cap\left[g_{p}, h_{m_{p}}\right]_{\perp} \text { is dense in } \overline{V_{p}+W_{p}} ;}
\end{aligned}
$$

indeed setting $f_{m_{p}}=g_{p}-g_{p}\left(w_{m_{p}}\right) h_{m_{p}}$ we have (12). 
We easily have (13) if $w_{m_{p}} \notin \overline{V_{p}+W_{p} \cap\left[g_{p}\right]_{\perp}}$; indeed in this case $w_{m_{p}} \notin U_{p}+$ $\overline{V_{p}+W_{p} \cap\left[g_{p}\right]_{\perp}}$ because by (6) $U_{p} \cap \overline{V_{p}+W_{p}}=\{0\}$; hence there exists $h_{m_{p}}$ so that $h_{m_{p}}\left(w_{m_{p}}\right)=1, U_{p}+\overline{V_{p}+W_{p} \cap\left[g_{p}\right]_{\perp}} \subset\left[h_{m_{p}}\right]_{\perp}$. Therefore by (8) and (11) it follows that

$$
\left[w_{m_{p}}\right]+W_{p} \cap\left[g_{p}, h_{m_{p}}\right]_{\perp}=\left[w_{m_{p}}\right]+W_{p} \cap\left[g_{p}\right]_{\perp}=W_{p}
$$

and

$$
\left[v_{m_{p}}\right]+V_{p} \cap\left[g_{p}, h_{m_{p}}\right]_{\perp}=\left[v_{m_{p}}\right]+V_{p} \cap\left[g_{p}\right]_{\perp}=V_{p}
$$

that is $(13)$ is proved.

Let us now prove (13) when

$$
w_{m_{p}} \in \overline{V_{p}+W_{p} \cap\left[g_{p}\right]_{\perp}} .
$$

By (11) $w_{m_{p}} \notin\left[g_{p}\right]_{\perp}$; moreover by (6) and by hypothesis $V_{p} \cap W_{p}=\{0\}$; hence $w_{m_{p}} \notin\left[v_{m_{p}}\right]+W_{p} \cap\left[g_{p}\right]_{\perp}$. On the other hand, by (6) $U_{p} \cap \overline{V_{p}+W_{p}}=\{0\}$; hence $w_{m_{p}} \notin U_{p}+\left[v_{m_{p}}\right]+W_{p} \cap\left[g_{p}\right]_{\perp}$; therefore there exists $h_{m_{p}}$ so that

$$
h_{m_{p}}\left(w_{m_{p}}\right)=1, \quad U_{p}+\left[v_{m_{p}}\right]+W_{p} \cap\left[g_{p}\right]_{\perp} \subset\left[h_{m_{p}}\right]_{\perp} .
$$

We claim that by (13) and (15) it is sufficient to verify that

$$
\left[w_{m_{p}}\right]+\overline{V_{p} \cap\left[h_{m_{p}}\right]_{\perp}+W_{p} \cap\left[g_{p}\right]_{\perp}}=\left[w_{m_{p}}\right]+\overline{V_{p}+W_{p} \cap\left[g_{p}\right]_{\perp}} .
$$

Indeed by (15) $W_{p} \cap\left[g_{p}, h_{m_{p}}\right]_{\perp}=W_{p} \cap\left[g_{p}\right]_{\perp}$; moreover by (11) $w_{m_{p}} \notin\left[g_{p}\right]_{\perp}$ and by (8) $w_{m_{p}} \in W_{p}$; hence $\left[w_{m_{p}}\right]+W_{p} \cap\left[g_{p}\right]_{\perp}=W_{p}$. On the other hand, by (15) $v_{m_{p}} \in V_{p} \cap\left[h_{m_{p}}\right]_{\perp} ;$ that is, by (8) $\left[v_{m_{p}}\right]+V_{p} \cap\left[g_{p}, h_{m_{p}}\right]_{\perp}=V_{p} \cap\left[h_{m_{p}}\right]_{\perp}$.

By (14) and (15) there exist $v_{p}^{\prime}$ and $w_{p}^{\prime}$ so that $h_{m_{p}}\left(v_{p}^{\prime}\right)=h_{m_{p}}\left(w_{m_{p}}\right)=1$ with $v_{p}^{\prime} \in V_{p}$ and $w_{m_{p}}=v_{p}^{\prime}+w_{p}^{\prime}$ with $w_{p}^{\prime} \in \overline{V_{p} \cap\left[h_{m_{p}}\right]_{\perp}+W_{p} \cap\left[g_{p}\right]_{\perp}}$, therefore $V_{p}=\left[v_{p}^{\prime}\right]+V_{p} \cap\left[h_{m_{p}}\right]_{\perp}$ and $v_{p}^{\prime} \in\left[w_{m_{p}}\right]+\overline{V_{p} \cap\left[h_{m_{p}}\right]_{\perp}+W_{p} \cap\left[g_{p}\right]_{\perp}}$, which completes the proof of (16) and therefore of (12).

Set

$Z_{p}=U_{p}+\left[v_{m_{p}}, w_{m_{p}}\right], \quad V_{p}^{\prime}=Z_{p}+V_{p} \cap\left[f_{m_{p}}, h_{m_{p}}\right]_{\perp}, \quad W_{p}^{\prime}=Z_{p}+W_{p} \cap\left[f_{m_{p}}, h_{m_{p}}\right]_{\perp} ;$ by (6) and (12) $V_{p}^{\prime} / Z_{p}$ and $W_{p}^{\prime} / Z_{p}$ are quasi complementary subspaces of $B / Z_{p}$. Hence by Theorem IV ${ }^{*}$ there exist $\left(v_{p n}^{\prime}, w_{p n}^{\prime}\right)_{n>m_{p}}$ of $B$ and $\left(F_{p n}, H_{p n}\right)_{n>m_{p}}$ of $\left(B / Z_{p}\right)^{*}$ so that $\left(v_{p n}^{\prime}+Z_{p}, F_{p n}\right)_{n>m_{p}} \cup\left(w_{p n}^{\prime}+Z_{p}, H_{p n}\right)_{n>m_{p}}$ is biorthogonal and $\left(v_{p n}^{\prime}+Z_{p}\right)_{n>m_{p}} \cup\left(w_{p n}^{\prime}+Z_{p}\right)_{n>m_{p}}$ is an $M$-basis of $B / Z_{p}$, with $\left(v_{p n}^{\prime}\right)_{n>m_{p}} \subset$ $V_{p} \cap\left[f_{m_{p}}, h_{m_{p}}\right]_{\perp}$ and $\left(w_{p n}^{\prime}\right)_{n>m_{p}} \subset W_{p} \cap\left[f_{m_{p}}, h_{m_{p}}\right]_{\perp}$. Since $\left(\bar{x}_{n}\right)$ is complete in $\overline{V+W}$ there exists an integer $m_{p+1}>m_{p}$ so that by (1), setting $v_{n}=v_{p n}^{\prime}$ and $w_{n}=w_{p n}^{\prime}$ for $m_{p}+1 \leq n \leq m_{p+1}-1$, it follows that

$$
\operatorname{dist}\left(\bar{x}_{n}, U+\left[v_{k}, w_{k}\right]_{k=1}^{m_{p+1}-1}\right)<1 / 2^{p} \text { for } 1 \leq n \leq p .
$$

In order to have (6) for $p+1$ it is now sufficient to set, for $m_{p+1} \leq n \leq m_{p+1}-1$, $f_{n}(x)=F_{p n}\left(x+Z_{p}\right)$ and $h_{n}(x)=H_{p n}\left(x+Z_{p}\right)$ for every $x$ of $B$; moreover

$$
\begin{gathered}
U_{p+1}=U_{p}+\left[v_{n}, w_{n}\right]_{n=m_{p}}^{m_{p+1}-1}, \quad V_{p+1}=V_{p} \cap\left[f_{n}, h_{n}\right]_{n=m_{p}}^{m_{p+1}=1}, \\
W_{p+1}=W_{p} \cap\left[f_{n}, h_{n}\right]_{n=m_{p}}^{m_{p+1}-1} .
\end{gathered}
$$

This completes the proof of Lemma 7.

The next lemma provides the key for the proof of Theorem III. 
LEMMA 8. Let $U, V, W$ be quasi complementary subspaces of $B$, with $U$ of finite dimension and $\operatorname{dist}(S(V), S(W))=0$. Then for every $\varepsilon>0$ there exist $v_{1}$ in $S(V)$, $w_{1}$ in $S(W)$, a subspace $V_{1}$ of $V$ and a subspace $W_{1}$ of $W$, with $l_{1}$ and $g_{1}$ in $B^{*}$, so that $\left(v_{1}, l_{1}\right) \cup\left(w_{1}, g_{1}\right)$ is biorthogonal, $U+V_{1}+W_{1} \subset\left[l_{1}, g_{1}\right]_{\perp},\left\|l_{1}\right\|<1+\varepsilon$, $\left\|g_{1}\right\|<1+\varepsilon,\left[v_{1}, w_{1}\right]+\overline{V_{1}+W_{1}}=B$.

PROOF. By Theorem $\mathrm{V}^{*}$ there exists $v_{1}$ in $S(V)$ with $\operatorname{dist}\left(v_{1}, U\right)=1$. We claim that there exists $l_{1}$ in $B^{*}$ so that

$$
l_{1}\left(v_{1}\right)=1, \quad\left\|l_{1}\right\|<1+\varepsilon, \quad U \subset\left[l_{1}\right]_{\perp}, \quad \overline{V+W \cap\left[l_{1}\right]_{\perp}}=\overline{V+W} .
$$

Let $\tilde{l}_{1} \in B^{*}$ so that

$$
\tilde{l}_{1}\left(v_{1}\right)=1=\left\|\tilde{l}_{1}\right\|, \quad U \subset\left[\tilde{l}_{1}\right]_{\perp} .
$$

If $\overline{V+W \cap\left[\tilde{l}_{1}\right]_{\perp}}=\overline{V+W}$ the claim is already proved; otherwise there exists $\tilde{w}$ so that

$$
\tilde{w} \in S(W), \quad W=[\tilde{w}]+W \cap\left[\tilde{l}_{1}\right]_{\perp}, \quad \tilde{w} \notin \overline{V+W \cap\left[\tilde{l}_{1}\right]_{\perp}} .
$$

By Lemma 7 there exist sequences $\left(\tilde{v}_{n}\right),\left(v_{n}^{\prime}\right),\left(\tilde{w}_{n}\right),\left(w_{n}^{\prime}\right)$ of $B$ and $\left(f_{n}\right)$ of $B^{*}$ so that

$$
\begin{aligned}
& \left(\tilde{v}_{n}\right) \cup\left(v_{n}^{\prime}\right) \cup\left(\tilde{w}_{n}\right) \cup\left(w_{n}^{\prime}\right) \text { is minimal and complete in } \\
& \qquad \cap\left[\tilde{l}_{1}\right]_{\perp}+W \cap\left[\tilde{l}_{1}\right]_{\perp} \\
& \text { with }\left(\tilde{v}_{n}\right) \cap\left(v_{n}^{\prime}\right) \subset S\left(V \cap\left[\tilde{l}_{1}\right]_{\perp}\right) \text { and }\left(\tilde{w}_{n}\right) \cup\left(w_{n}^{\prime}\right) \subset S\left(W \cap\left[\tilde{l}_{1}\right]_{\perp}\right) \\
& \left\|\tilde{v}_{n}+\tilde{w}_{n}\right\|<1 / 4^{n}, \quad f_{n}\left(\tilde{w}_{n}\right)=1=\left\|f_{n}\right\|, \\
& U+\left[v_{1}, \tilde{w}\right]+\left[\left(v_{k}^{\prime}, w_{k}^{\prime}\right) \cup\left(\tilde{v}_{k}, \tilde{w}_{k}\right)_{k \neq n}\right] \subset\left[f_{n}\right]_{\perp} \quad \text { for every } n .
\end{aligned}
$$

If $\bar{n}$ is a positive integer so that $1 / 2^{\bar{n}}<\varepsilon$ set

$$
\begin{aligned}
& v_{n}=\tilde{v}_{n}+f_{n}\left(\tilde{v}_{n}\right) l_{1}(\tilde{w}) v_{1} / 2^{n} \quad \text { and } \quad w_{n}=\tilde{w}_{n}+\tilde{w} / 2^{n} \quad \text { for } n>\bar{n} \\
& V_{0}=\overline{\left[v_{n}^{\prime}\right]+\left[\tilde{v}_{n}\right]_{n=1}^{\bar{n}}+\left[v_{n}\right]_{n>\bar{n}}} \quad \text { and } \quad W_{0}=\overline{\left[w_{n}^{\prime}\right]+\left[\tilde{w}_{n}\right]_{n=1}^{\bar{n}}+\left[w_{n}\right]_{n>\bar{n}}} .
\end{aligned}
$$

We are going to prove that $\left[v_{1}\right]+V_{0}+W_{0}$ is dense in $\overline{V+W}$. By $(20)$ it follows that

$$
\lim _{n \rightarrow \infty} 2^{n}\left(v_{n}+w_{n}\right)=\lim _{n \rightarrow \infty}\left(2^{n}\left(\tilde{u}_{n}+\tilde{w}_{n}\right)+f_{n}\left(\tilde{v}_{n}\right) \tilde{l}_{1}(\tilde{w}) v_{1}+\tilde{w}\right)=\tilde{w}-\tilde{l}_{1}(\tilde{w}) v_{1}
$$

indeed $\left\|2^{n}\left(\tilde{v}_{n}+\tilde{w}_{n}\right)\right\|<1 / 2^{n}$ and $f_{n}\left(\tilde{v}_{n}\right)=f_{n}\left(\tilde{v}_{n}+\tilde{w}_{n}\right)-1$ with $\left|f_{n}\left(\tilde{v}_{n}+\tilde{w}_{n}\right)\right|<$ $1 / 4^{n}$, for every $n$. Therefore $\tilde{w}-\tilde{l}_{1}(\tilde{w}) v_{1} \in\left[\left(v_{n}\right)_{n>\bar{n}} \cup\left(w_{n}\right)_{n>\bar{n}}\right]$; hence by $(20)$ and (21) $\tilde{w} \cup\left(\tilde{w}_{n}\right)_{n>\bar{n}} \cup\left(\tilde{v}_{n}\right)_{n>\bar{n}} \subset\left[v_{1} \cup\left(v_{n}, w_{n}\right)_{n>\bar{n}}\right]$; that is by (18)-(21) $\left[v_{1}\right]+$ $\overline{V_{0}+W_{0}}=\overline{V+W}$. Set now

$$
l_{1}=\tilde{l}_{1}-\sum_{n=\bar{n}+1}^{\infty} \frac{\tilde{l}_{1}(\tilde{w})}{2^{n}} f_{n} ;
$$

for every $n>\bar{n}$ by (18), (20) and (21) it follows that

$$
\begin{aligned}
l_{1}\left(v_{n}\right) & =\left(\tilde{l}_{1}-\sum_{k=\bar{n}+1}^{\infty} \frac{\tilde{l}_{1}(\tilde{w})}{2^{k}} f_{k}\right)\left(\tilde{v}_{n}\right)+\left(\tilde{l}_{1}-\sum_{k=\bar{n}+1}^{\infty} \frac{\tilde{l}_{1}(\tilde{w})}{2^{k}} f_{k}\right)\left(\frac{f_{n}\left(\tilde{v}_{n}\right) \tilde{l}_{1}(\tilde{w})}{2^{n}} v_{1}\right) \\
& =-f_{n}\left(\tilde{v}_{n}\right) \tilde{l}_{1}(\tilde{w}) / 2^{n}+f_{n}\left(\tilde{v}_{n}\right) \tilde{l}_{1}(\tilde{w}) \tilde{l}_{1}\left(v_{1}\right) / 2^{n}=0, \\
l_{1}\left(w_{n}\right) & =\tilde{l}_{1}(\tilde{w}) / 2^{n}-f_{n}\left(\tilde{w}_{n}\right) \tilde{l}_{1}(\tilde{w}) / 2^{n}=0 .
\end{aligned}
$$


Therefore by (18), (20), and (21) $U+V_{0}+W_{0} \subset\left[l_{1}\right]_{\perp}, l_{1}\left(v_{1}\right)=1$; that is in order to prove (17) it is sufficient to verify that $\left\|l_{1}\right\|<1+\varepsilon$. Indeed by (18), (19) and (20) we have that

$$
\left\|l_{1}\right\| \leq\left\|\tilde{l}_{1}\right\|+\sum_{n=\bar{n}+1}^{\infty}\left\|f_{n}\right\| \frac{\left|\tilde{l}_{1}(\tilde{w})\right|}{2^{n}}=1+\frac{\left|\tilde{l}_{1}(\tilde{w})\right|}{2^{\bar{n}}} \sum_{n=1}^{\infty} \frac{1}{2^{n}} \leq 1+\frac{1}{2^{\bar{n}}}<1+\varepsilon .
$$

This completes the proof of (17).

By Theorem $\mathrm{V}^{*}$ there exists $w_{1}$ of $S\left(W \cap\left[l_{1}\right]_{\perp}\right)$ with $\operatorname{dist}\left(w_{1}, U+\left[v_{1}\right]\right)=1$; hence, proceeding as for $v_{1}$ in (17), for $U+\left[v_{1}\right]$ instead of $U, W \cap\left[l_{1}\right]_{\perp}$ instead of $V, w_{1}$ instead of $v_{1}$ and $V \cap\left[l_{1}\right]_{\perp}$ instead of $W$, there exists $g_{1}$ in $B^{*}$ such that

$$
\begin{aligned}
& g_{1}\left(w_{1}\right)=1, \quad\left\|g_{1}\right\|<1+\varepsilon, \quad U+\left[v_{1}\right] \subset\left[g_{1}\right]_{\perp}, \\
& \overline{V \cap\left[l_{1}, g_{1}\right]_{\perp}+W \cap\left[l_{1}\right]_{\perp}}=\overline{V \cap\left[l_{1}\right]_{\perp}+W \cap\left[l_{1}\right]_{\perp}} \text {. }
\end{aligned}
$$

On the other hand by $(17)\left[v_{1}\right]+\overline{V \cap\left[l_{1}\right]_{\perp}+W \cap\left[l_{1}\right]_{\perp}}=\overline{V+W \cap\left[l_{1}\right]_{\perp}}=\overline{V+W}$, moreover $W \cap\left[l_{1}\right]_{\perp}=\left[w_{1}\right]+W \cap\left[l_{1}, g_{1}\right]_{\perp}$; that is

$$
\left[v_{1}\right]+\left[w_{1}\right]+\overline{V \cap\left[l_{1}, g_{1}\right]_{\perp}+W \cap\left[l_{1}, g_{1}\right]_{\perp}}=\overline{V+W} .
$$

Therefore it is sufficient to set $V_{1}=V \cap\left[l_{1}, g_{1}\right]_{\perp}$ and $W_{1}=W \cap\left[l_{1}, g_{1}\right]_{\perp}$; which completes the proof of Lemma 8.

ProOF OF THEOREM III. If $\operatorname{dist}(S(X), S(Y))>0$ the thesis is obvious, hence suppose that dist $(S(X), S(Y))=0$. Our aim is to pick an increasing sequence $\left(m_{n}\right)$ of positive integers, two sequences $\left(v_{n}\right),\left(w_{n}\right)$ of $B$ and two sequences $\left(l_{n}\right),\left(g_{n}\right)$ of $B^{*}$, so that

$\left(v_{n}\right) \cup\left(w_{n}\right)$ is a 1 -norming $M$-basis of $B$, with $\left(v_{n}\right) \subset S(X)$,

$\left(w_{n}\right) \subset S(Y) ;\left(v_{n}, l_{n}\right) \cup\left(w_{n}, g_{n}\right)$ is biorthogonal, with $\left\|l_{m_{n}}\right\|<2$ and $\left\|g_{m_{n}}\right\|<2$ for every $n$.

Let $\left(\bar{u}_{n}\right)$ be a sequence complete in $B$.

Fix an integer $p>1$ and suppose we have an increasing sequence $\left(m_{n}\right)_{n=1}^{p}$ of integers with $m_{1}=1,\left(v_{n}, w_{n}\right)_{n=1}^{m_{p}-1}$ of $B,\left(l_{n}, g_{n}\right)_{n=1}^{m_{p}-1}$ of $B^{*}$, subspaces $X_{p}, Y_{p}$ of $B$ and a finite subset $H^{p-1}$ of $B^{*}$, so that

$$
\begin{aligned}
& \left(v_{n}, l_{n}\right)_{n=1}^{m_{p}-1} \cup\left(w_{n}, g_{n}\right)_{n=1}^{m_{p}-1} \text { is biorthogonal, with } \\
& \left(v_{n}\right)_{n=1}^{m_{p}-1} \subset S(X) \text { and }\left(w_{n}\right)_{n=1}^{m_{p}-1} \subset S(Y) ; \\
& \left\|l_{m_{n}}\right\|<2,\left\|g_{m_{n}}\right\|<2, \operatorname{dist}\left(\bar{u}_{n},\left[v_{k}, w_{k}\right]_{k=1}^{m_{p}-1}\right)<1 / 2^{p-1} \\
& \quad \text { for } 1 \leq n \leq p-1 ; \\
& X_{p}+Y_{p} \subset\left[\left(l_{n}, g_{n}\right)_{n p}^{m_{p}-1} \cup H^{p-1}\right]_{\perp}, \quad X_{p} \subset X, \\
& Y_{p} \subset Y, \quad\left[v_{n}, w_{n}\right]_{n=1}^{m_{p}-1}+\overline{X_{p}+Y_{p}}=B ; \\
& H^{p-1} \text { is }\left(1+1 / 2^{p-1}\right) \text {-norming on }\left[v_{n}, w_{n}\right]_{n=1}^{m_{p}-1} .
\end{aligned}
$$

We shall have (22) if for (23) we can proceed by induction; that is if it is possible to have (23) for $p=2$ and $p+1$, with $\left(v_{n}\right)_{n=m_{p}}^{m_{p+1}-1} \subset X_{p}$ and $\left(w_{n}\right)_{n=m_{p}}^{m_{p+1}-1} \subset Y_{p}$. We can describe the induction by only one step, since the construction of (23) for $p=2$ becomes a particular case of the general procedure if we use the convention that for $p=1$ we mean the initial situation, where the sequences $\left(v_{n}, w_{n}, l_{n}, g_{n}\right)_{n=1}^{m_{p}-1}$ and the set $H^{p-1}$ do not appear; hence $X_{1}=X$ and $Y_{1}=Y$. 
We now prove the existence of (23) for $p+1$ instead of $p$. By Lemma 8 there exist $v_{m_{p}}, w_{m_{p}}$ of $B$, subspaces $V_{p}, W_{p}$ of $B$ and $l_{m_{p}}, g_{m_{p}}$ of $B^{*}$, so that $\left(v_{n}, l_{n}\right)_{n=1}^{m_{p}} \cup$ $\left(w_{n}, g_{n}\right)_{n=1}^{m_{p}}$ is biorthogonal, with $v_{m_{p}} \in S\left(X_{p}\right)$ and $w_{m_{p}} \in S\left(Y_{p}\right) ; V_{p} \subset X_{p}$, $W_{p} \subset Y_{p}, \overline{V_{p}+W_{p}}+\left[v_{n}, w_{n}\right]_{n=1}^{m_{p}}=B ; V_{p}+W_{p} \subset\left[l_{m_{p}}, g_{m_{p}}\right]_{\perp},\left\|l_{m_{p}}\right\|<2$ and $\left\|g_{m_{p}}\right\|<2$. Let $H^{p}$ be a finite subset of $B^{*}$ which is $\left(1+1 / 2^{p}\right)$-norming on $\left[v_{n}, w_{n}\right]_{n=1}^{m_{p}}$. Set

$$
Z_{p}=\left[v_{n}, w_{n}\right]_{n=1}^{m_{p}}+\overline{V_{p} \cap H_{\perp}^{p}+W_{p} \cap H_{\perp}^{p}} .
$$

There exist $\left(v_{n}\right)_{n=m_{p}+1}^{m_{p}^{\prime}}$ in $S\left(V_{p}\right)$ and $\left(w_{n}\right)_{n=m_{p}+1}^{m_{p}^{\prime \prime}}$ in $S\left(W_{p}\right)$ so that $\left(v_{n}+Z_{p}\right)_{n=m_{p}+1}^{m_{p}^{\prime}}$ $\cup\left(w_{n}+Z_{p}\right)_{n=m_{p}+1}^{m_{p}^{\prime \prime}}$ is an $M$-basis of $B / Z_{p},\left[v_{n}\right]_{n=m_{p}+1}^{m_{p}^{\prime}}+\left[w_{n}\right]_{n=m_{p}+1}^{m_{p}^{\prime \prime}}+Z_{p}=B$. Now we use Theorem II* twice, "in the direction" of $V_{p} \cap H_{\perp}^{p}$, and afterwards in the direction of $W_{p} \cap H_{\perp}^{p}$; then there will exist $\left(v_{p n}\right)_{n>m_{p}^{\prime}} \subset S\left(V_{p} \cap H_{\perp}^{p}\right)$, $\left(w_{p n}\right)_{n>m_{p}^{\prime \prime}} \subset S\left(W_{p} \cap H_{\perp}^{p}\right)$, with $\left(l_{n}\right)_{n=m_{p}+1}^{m_{p}^{\prime}} \cup\left(l_{p n}\right)_{n>m_{p}^{\prime}} \cup\left(g_{n}\right)_{n=m_{p}+1}^{m_{p}^{\prime \prime}} \cup\left(g_{p n}\right)_{n>m_{p}^{\prime \prime}}$ in $B^{*}$ so that by (23) we have $\left(v_{n}\right)_{n=1}^{m_{p}^{\prime}} \cup\left(w_{n}\right)_{n=1}^{m_{p}^{\prime \prime}} \cup\left(v_{p n}\right)_{n>m_{p}^{\prime}} \cup\left(w_{p n}\right)_{n>m_{p}^{\prime \prime}}$ is an $M$-basis of $B$, with $\left(v_{n}, l_{n}\right)_{n=1}^{m_{p}^{\prime}} \cup\left(w_{n}, g_{n}\right)_{n=1}^{m_{p}^{\prime \prime}} \cup\left(v_{p n}, l_{p n}\right)_{n>m_{p}^{\prime}} \cup\left(w_{p n}, g_{p n}\right)_{n>m_{p}^{\prime \prime}}$ biorthogonal.

Since $\left(\bar{u}_{n}\right)$ is complete in $B$, there exists an integer $m_{p+1}>m_{p}$ so that, setting $v_{n}=v_{p n}$ for $m_{p}^{\prime}+1 \leq n \leq m_{p+1}-1$ and $w_{n}=w_{p n}$ for $m_{p}^{\prime \prime}+1 \leq n \leq m_{p+1}-1$, it follows that

$$
\operatorname{dist}\left(\bar{u}_{n},\left[v_{k}, w_{k}\right]_{k=1}^{m_{p+1}-1}\right)<1 / 2^{p} \text { for } 1 \leq n \leq p .
$$

In order to have (23) for $p+1$ it is sufficient to set $l_{n}=l_{p n}$ for $m_{p}^{\prime}<n<m_{p+1}$ and $g_{n}=g_{p n}$ for $m_{p}^{\prime \prime}<n<m_{p+1}$;

$$
X_{p+1}=\left[v_{p n}\right]_{n \geq m_{p+1}} \subseteq X \cap\left[\left(l_{n}, g_{n}\right)_{n=1}^{m_{p+1}-1} \cup H^{p}\right]_{\perp}
$$

and

$$
Y_{p+1}=\left[w_{p n}\right]_{n \geq m_{p+1}} \subseteq Y \cap\left[\left(l_{n}, g_{n}\right)_{n=1}^{m_{p+1}-1} \cup H^{p}\right]_{\perp} .
$$

This completes the proof of (22).

Now it is sufficient to apply Theorem I* to (22) and we have that there exist two block perturbations $\left(x_{n}\right)$ and $\left(y_{n}\right)$ of $\left(v_{n}\right)$ and $\left(w_{n}\right)$, respectively, so that $\left(x_{n}\right) \cup\left(y_{n}\right)$ becomes uniformly minimal; on the other hand $\left(x_{n}\right) \cup\left(y_{n}\right)$ is still a 1-norming $M$ basis of $B$; which completes the proof of Theorem III.

ProOF OF Proposition 5. By the example of [19] there exists a Banach space $B_{0}$ with two quasi complementary infinite dimensional subspaces $X$ and $Y$ so that

$$
\left(z_{n}\right) \subset S(Y) \text { implies that }\left(z_{n}+X\right) \text { has a convergent subsequence. }
$$

Fix $\varepsilon>0$ and let $\left(y_{n}\right)$ be complete in $Y$. We claim that there exists an integer $n_{\varepsilon}$ so that

$$
\operatorname{dist}\left(S\left(\left[y_{n}\right]_{n>n_{\varepsilon}}\right), X+\left[y_{n}\right]_{n=1}^{n_{\varepsilon}}\right)<\varepsilon ;
$$

in this case the thesis will be verified for the subspaces $X_{\varepsilon}=X+\left[y_{n}\right]_{n=1}^{n_{\varepsilon}}$ and $Y_{\varepsilon}=\left[y_{n}\right]_{n>n_{\varepsilon}}$. If $(25)$ is not true there exists $\left(n_{k}\right) \subseteq(n)$ so that

$$
\operatorname{dist}\left(z_{k}, X+\left[y_{i}\right]_{i=1}^{n_{k}}\right) \geq \varepsilon \text { with } z_{k} \in S\left(\left[y_{i}\right]_{i>n_{k}}\right) \text { for every } k \text {; }
$$

but this implies that $\left(z_{k}+X\right)$ cannot have a convergent subsequence, which contradicts (24). This completes the proof of Proposition 5. 


\section{BIBLIOGRAPHY}

1. S. Banach, Théorie des opérations linéaires, Chelsea, New York, 1932.

2. W. J. Davis and W. B. Johnson, On the existence of fundamental and total bounded biorthogonal systems in Banach spaces, Studia Math. 45 (1973), 173-179.

3. P. Enflo, A counterexample to the approximation problem in Banach spaces, Acta Math. 130 (1973), 309-317.

4. M. A. Krasnoselskii, M. G. Krein and D. P. Milman, On defect numbers of linear operators in a Banach space and on some geometric problems, Sb. Trud. Inst. Matem. Akad. Nauk Ukr. SSR 11 (1948), 97-112.

5. J. Lindenstrauss and L. Tzafriri, Classical Banach spaces. I, Springer-Verlag, Berlin and New York, 1977.

6. G. W. Mackey, Note on a theorem of Murray, Bull. Amer. Math. Soc. 52 (1946), 322-325.

7. A. Markushevich, Sur les bases (au sens large) dans les especes linéaires, Dokl. Akad. Nauk SSSR 41 (1943), 227-229.

8. V. D. Milman, Geometric theory of Banach spaces. I, Russian Math. Surveys 25 (1970), 111-170.

9. R. I. Ovsepian and A. Pełczynski, On the existence of a fundamental total and bounded biorthogonal sequence in every separable Banach space, and related constructions of uniformly bounded orthonormal systems in $L^{2}$, Studia Math. 54 (1975), 149-159.

10. A. Pelczynski, All separable Banach spaces admit for every $\varepsilon>0$ fundamental total and bounded by $1+\varepsilon$ biorthogonal sequences, Studia Math. 55 (1976), 295-304.

11. I. Singer, Best approximation in normed linear spaces by elements of linear subspaces, Springer-Verlag, Berlin and New York, 1971.

12. , On biorthogonal systems and total sequences of functionals, Math. Ann. 193 (1971), 183-188.

13. __ Bases in Banach spaces. II, Springer-Verlag, Berlin and New York, 1981.

14. A. Sobczyk, Projection of the space $m$ on its subspace $c_{0}$, Bull. Amer. Math. Soc. 47 (1941), 938-947.

15. P. Terenzi, Properties of structure and completeness, in a Banach space, of the sequences without an infinite minimal subsequence, Ist. Lombardo Accad. Sci. Lett. Rend. A 112 (1978), 42-66.

16. __ Biorthogonal systems in Banach spaces, Riv. Mat. Univ. Parma (4) 4 (1978), 165204.

17. Some completeness properties of general sequences in a Banach space, Bollettino UMI 5 (15-B) (1978), 743-753.

18. __ On bounded and total biorthogonal systems spanning given subspaces, Accad. Naz. dei Lincei (Rend. Sc.) 58 (1979), 168-178.

19. _ Extension of uniformly minimal $M$-basic sequences in Banach spaces, J. London Math. Soc. 27 (1983), 500-506.

20. W. A. Veech, Short proof of Sobczyk's theorem, Proc. Amer. Math. Soc. 28 (1971), 627-628.

21. V. S. Vinokurov, On biorthogonal systems spanning a given subspace, Dokl. Akad. Nauk SSSR 85 (1952), 685-689.

22. A. Wilansky, Functional analysis, Blaisdell, Waltham, Mass., 1964.

23.

24. M. Zippin, The separable extension problem, Israel J. Math. 26 (1977), 372-387.

Dipartimento di Matematica del Politecnico di Milano, Piazza leonardo DA VINCI 32-20133 MilANO, ITALY 